\title{
Learning the Language of Games
}

\author{
Jack Murray
}

School of English, UCC

\section{What do I do?}

When people ask me what I do for a living I give my answer in phases. I start with the vague, though technically accurate, answer that I am a $\mathrm{PhD}$ student. When this invariably leaves my questioner unsatisfied the second question follows swiftly: "Well what are you studying?" again I will dissemble and answer that I study literature. This answer satisfies many and I breathe a sigh of relief, but for some this is still too vague. When pressed on what kind of literature I offer up my last line of defence and answer that the specific object of my research is video games. For those who have already pursued the question this far, it is of course unthinkable that they not pursue it further, especially after so sudden and unexpected a twist. Broken and defeated, I am left with no other choice than to answer their questions in detail and at that point it all becomes a bit... academic.

\section{Video Games? Really?}

My final answer is often met with a certain amount of surprise, even incredulity. "I thought you said you studied literature!". To many people my academic background of English literature, philosophy and literary theory seems like a strange match for my chosen field of research. People ask if I am really a computer scientist and when I say that I am not their confusion only grows.

Video games and literature meet on contentious ground. The question of whether or not games are art (or can be art) is one that has been debated by academics and within the media for some time with no argument scoring a decisive victory. In spite of their ever increasing commercial success and the fact that they have been a part of our cultural milieu for over forty years games are still treated with suspicion by cultural commentators. As recently as January 2014 The Guardian newspaper featured an article arguing against recognizing games as art and film critic Roger Ebert's 2005 claim that games could never be art has achieved lasting infamy among advocates of game culture.

My own position on the matter - typically for an academic - requires some explanation. Given my chosen career path it should be clear which side of the debate I favour but the question of whether or not games are art, or can be art, or should be art, is not one that 
can be reduced to a simple yes or no answer. The umbrella term 'game' and the cultural space that it refers to encompasses a broad range of media categories, many of which are as different from each other as they are to more traditional media like film or the novel. Attempts to create a coherent definition of just what a game is have been stymied by this diversity for almost as long as games have been the subject of disciplined study.

Yes, I believe video games have the capacity to be art but that does not mean I believe that every game is art or even that every game should aspire to the status of art. Some games are better understood as sports, some as toys and some defy categorization altogether. It would be a disservice to the diversity of games and the imagination of those who create them to attempt to force a definition as art upon all of them, just as it is a disservice to unilaterally deny them recognition within that cultural space.

It is important too not to valorise those games that deliberately seek to belong in the artistic space over those with other priorities. Games are a diverse medium suited to many different kinds of cultural expression. The question of whether or not games are art is really only one part of a larger investigation.

\section{"I study literature."}

Literary theory may seem like a strange lens to apply to the study of video games but it is an approach that has already yielded a surprisingly large body of work. The academic discipline of game studies has its roots in literature departments, other researchers like me who wanted to tackle the mystery of games' uncertain cultural status using the tools with which they were familiar. Literary theory offers many surprisingly productive approaches to the study of games and many of these interactions had been mapped out well before my own research commenced. My research focuses on a specific subset of literary theories, those that are concerned with the figure of the author, and what these theories can offer the ongoing effort to map the language of games.

\section{The Author}

What is an author? This is a deceptively complex question. In the two years I have been pursuing my research it is one to which I have heard many and varied answers. Theories of authorship go back as far as the works of Plato but close scrutiny of who, or what, the author is is primarily associated with certain French thinkers of the 20th century and the set of methodologies that are collectively referred to as Critical Theory.

In the model of authorship proposed by these theorists the author is an imposer of limits. There is a distinction drawn between an act of writing, which is viewed by these theorists not as the creation of brand new material but the arranging of pre-existing material in 
novel patterns, and an act of authorship. To be an author is to claim ownership not only of a work, but also of all the possible meanings of that work. The author is a figure who defines — but in doing so, limits — meaning.

The original theorists put forth this definition as part of an attack on traditional understandings of authorship. Though the vigour of that attack has died down in the half century since it was first put to paper many of the concepts it introduced remain useful to cultural theorists such as myself and the author remains a figure subject to much academic enquiry.

\section{Games and The Author}

The lens of authorship can offer much when it comes to the investigation of games but games have much to offer the study of the Author in turn. Games are a challenging space for authorial expression because compared with older media they offer the user an unprecedented level of involvement in the process of creating meaning. Though no-one has been able to settle on a stable definition of what a game is, most would agree that it is a common characteristic of games that they facilitate play.

Play itself is something of a vexed term when it comes to definitions but can broadly be understood as a balance between freedom and structure. Play is made possible by the imposition of rules. This is as true of simple children's games like Tag as it is of more complex games, including video games. Rules create a framework within which play can take place but within that framework players are free to express themselves and explore the limits of the system they have chosen to participate in.

Play, therefore, is reminiscent of the Author-Reader relationship. Authors provide stability, a limit on possible interpretations of their work but within those limits the reader is free to take their own meaning. Authors are the rules and readers the players. This parallel was drawn in the original texts in which the theories of authorship that I deal with were first put forward but it could not be claimed that it was done with any foresight of what was to come. Game theorists have largely dismissed the literary appropriation of 'play' as a workable methodology for the study of games.

Nonetheless, fruitful work can be found in the study of game authorship. Questions present themselves immediately. Who is the Author of a video game? Is it the designer? The programmer? What of the writer and the artist? Does the player have a role in the authorial process? Do games have authors at all? Going in the other direction we can ask what games have to offer theories of authorship. Games offer a new perspective from which we can examine the figure of the author and the relationship between author and reader. 


\section{The Product}

Which leaves perhaps the most important questions: why is any of this important? Who will benefit from my research? My specific aim is to produce a document that will be of use to game developers and that will facilitate the creation of better game content.

From my interactions with industry professionals as well as from the games I play it has become apparent to me that, although it has not yet been strongly identified as such, the question of authorship is one of great importance to the continuing development of games as a form of cultural expression. In order to better understand how the games industry is grappling with this issue I am gathering data by means of two surveys, one aimed at developers and one at gamers. The purpose of these surveys is to quantify these groups' understanding of authorship and how it effects their work and play. Equipped with this data I aim to unpack the issue of authorship in games in a way that is industry focused. Many games grapple with the role of the author, sometimes deliberately but more often incidentally. I aim to facilitate developers and gamers alike by further developing the critical tools through which the concept of authorship can be better understood specifically in relation to games.

The knotted issue of authorship is one that the gaming medium, by its very nature, cannot help but engage with. The importance of the author-consumer relationship is hard-wired into the medium at the most fundamental level, in a way that is simply not true of other media. Game developers already recognize the great importance of this relationship but the language to engage effectively with it remains underdeveloped. It is the aim of my research to document and clarify the different types of authorial expression made possible through games and, through a better understanding of the author-player relationship, to facilitate our understanding of games as a vital contributor to our culture. 